\title{
TNFAIP3 F127C Coding Variation in Greek Primary Sjogren's Syndrome Patients
}

\author{
Adrianos Nezos $\mathbb{D}^{1},{ }^{1}$ Eliona Gkioka, ${ }^{1}$ Michael Koutsilieris ${ }^{(D},{ }^{1}$ Michael Voulgarelis, ${ }^{2}$ \\ Athanasios G. Tzioufas, ${ }^{2}$ and Clio P. Mavragani ${ }^{10,2,3}$ \\ ${ }^{1}$ Department of Physiology, School of Medicine, National and Kapodistrian University of Athens, Athens, Greece \\ ${ }^{2}$ Department of Pathophysiology, School of Medicine, National and Kapodistrian University of Athens, Athens, Greece \\ ${ }^{3}$ Joint Academic Rheumatology Program, National and Kapodistrian University of Athens, School of Medicine, Athens, Greece
}

Correspondence should be addressed to Adrianos Nezos; anezos@med.uoa.gr

Received 21 June 2018; Accepted 29 October 2018; Published 19 December 2018

Academic Editor: Eduardo F. Borba

Copyright ( 2018 Adrianos Nezos et al. This is an open access article distributed under the Creative Commons Attribution License, which permits unrestricted use, distribution, and reproduction in any medium, provided the original work is properly cited.

\begin{abstract}
Tumor necrosis factor, alpha-induced protein 3 (TNFAIP3) gene encodes the A20 protein, an important negative feedback regulator of the nuclear factor kappa-light-chain-enhancer of activated B cell (NF- $\kappa \mathrm{B})$ pathway. A coding TNFAIP3 variant, namely rs2230926, has been previously linked to B cell non-Hodgkin's lymphoma (NHL) development in patients with Sjogren's syndrome (SS) of French and UK origin. Herein, we aimed to determine the prevalence of rs2230926 in a Greek primary SS cohort and explore possible associations with disease characteristics. The rs2230926 gene variant was genotyped in 327 primary Greek SS patients (ninety-one complicated by NHL (SS-lymphoma)) and 448 Greek healthy controls (HC) of similar age and sex distribution. Clinical and laboratory characteristics were also recorded and gene expression of relevant genes of the NF- $\kappa$ B pathway was quantitated by real-time PCR in available whole peripheral blood (PB) from 165 primary SS patients. Increased prevalence of the rs2230926 mutant variant was detected in both SS-lymphoma and SS-nonlymphoma subgroups compared to HC ( $8.8 \%$ vs. $7.6 \%$ vs. $3.6 \%$, $p$ values: 0.04 and 0.03 , respectively) in association with higher IgM, LDH serum levels, and PB Bcl-XL transcripts but lower leucocyte and neutrophil counts. Of interest, approximately one-fifth of SSlymphoma cases with age at disease onset $\leq 40$ years carried the rs 2230926 variant $(18.2 \%$ vs. 3.6\%, OR 95\% (CI): 6.0 (1.8-19.8), $p$ value: 0.01 ). We postulate that deregulation of the NF- $\kappa \mathrm{B}$ pathway as a result of the TNFAIP3 rs 2230926 aberration increases SS and SS lymphoma susceptibility particularly in patients with early disease onset.
\end{abstract}

\section{Introduction}

Primary Sjogren's syndrome (SS) - classically considered a chronic autoimmune exocrinopathy leading to oral and ocular dryness [1-3]-is also characterized by the highest susceptibility for B cell non-Hodgkin's lymphoma (NHL) among all autoimmune diseases [1-5]. Though several clinical, laboratory, and histopathological predictors have been identified over the last decades as reliable predictors for lymphoma development in these patients, the molecular events leading to malignant transformation remain elusive [5-10].

A growing body of evidence suggests that activation of the nuclear factor kappa-light-chain-enhancer of activated $\mathrm{B}$ cell $(\mathrm{NF}-\kappa \mathrm{B})$ pathway is a critical step in the pathogenesis of both primary SS and B cell hematological malignancies including B cell NHL, the major type of primary SS-related lymphomas. Recent studies revealed that B cell-activating factor-receptor $(B A F F-R)$ His159Tyr mutation and a tumor necrosis factor, alpha-induced protein 3 (TNFAIP3) germline coding variation-both associated with the activation of the $\mathrm{NF}-\kappa \mathrm{B}$ pathway-are important contributors in primary SS and SS-related lymphomagenesis [11-16].

The TNFAIP3 gene encodes the A20 protein essential for the development and functional performance of dendritic, B and T cells and macrophages as well as an important negative feedback regulator of the NF- $\kappa \mathrm{B}$ pathway [17]. A20-deficient mice die early due to multiorgan inflammation and cachexia as a result of excessive TNF-induced 
TABLE 1: Demographics of study participants (age and sex distributions).

\begin{tabular}{lccc}
\hline \multirow{2}{*}{ Participants } & \multicolumn{2}{c}{ SS patients $(n=327)$} & \multirow{2}{*}{ Healthy controls $(n=448)$} \\
\hline Age $($ mean years \pm SD) & SS-nonlymphoma $(n=236)$ & SS-lymphoma $(n=91)$ & $55.3 \pm 18.1$ \\
Female sex $(\%)$ & $59.5 \pm 13.7$ & $59.9 \pm 12.5$ & $86.0 \%$ \\
\hline
\end{tabular}

TABLE 2: Real-time PCR primers for gene expression quantification.

\begin{tabular}{|c|c|c|c|c|}
\hline Full gene name & Gene ID & Accession number & Forward primer & Reverse primer \\
\hline $\begin{array}{l}\text { Homo sapiens nuclear factor } \\
\text { kappa B subunit } 1 \text {, mRNA }\end{array}$ & $N F-\kappa B 1$ & NM_003998.3 & $\begin{array}{c}\text { CCTGAGACAAATGGGC } \\
\text { TACAC }\end{array}$ & $\begin{array}{c}\text { TTTAGGGCTTTGGTTT } \\
\text { ACACGG }\end{array}$ \\
\hline $\begin{array}{l}\text { Homo sapiens nuclear factor } \\
\text { kappa B subunit } 2 \text {, mRNA }\end{array}$ & $N F-\kappa B 2$ & NM_001077494.3 & $\begin{array}{c}\text { GAACTCCTCCATTGTG } \\
\text { GAACC }\end{array}$ & $\begin{array}{c}\text { ACCAGCGGTTGAAGCG } \\
\text { TTCC }\end{array}$ \\
\hline $\begin{array}{l}\text { Homo sapiens BCL2, } \\
\text { apoptosis regulator, mRNA }\end{array}$ & $B c l-2$ & NM_000633.2 & $\begin{array}{c}\text { TTGCTTTACGTGGCCT } \\
\text { GTTTC }\end{array}$ & $\begin{array}{c}\text { GAAGACCCTGAAGGAC } \\
\text { AGCCA }\end{array}$ \\
\hline $\begin{array}{l}\text { Homo sapiens B-cell } \\
\text { lymphoma-extra large mRNA }\end{array}$ & $B c l-X L / B c l 2 l 1$ & NM_138578.2 & $\begin{array}{c}\text { GCCACTTACCTGAATG } \\
\text { ACCACC }\end{array}$ & $\begin{array}{c}\text { ACCAGCGGTTGAAGCG } \\
\text { TTCC }\end{array}$ \\
\hline $\begin{array}{l}\text { Glyceraldehyde-3-phosphate } \\
\text { dehydrogenase }\end{array}$ & GAPDH & NM_002046 & $\begin{array}{c}\text { CAACGGATTTGGTCGT } \\
\text { ATT }\end{array}$ & $\begin{array}{c}\text { GATGGCAACAATATCC } \\
\text { ACTT }\end{array}$ \\
\hline
\end{tabular}

NF- $\kappa \mathrm{B}$ activation $[18,19]$. TNFAIP3 gene variants have been linked to the pathogenesis of both chronic inflammatory and autoimmune disorders [12, 13, 19-22] and B cell lymphomas [23-26].

The current study aims at evaluating the prevalence of the rs2230926 polymorphism in a Greek cohort of primary SS patients and exploring any possible associations with clinical and laboratory SS-related characteristics, B cell NHL development, as well as relevant target genes of the $\mathrm{NF}-\kappa \mathrm{B}$ pathway.

\section{Materials and Methods}

2.1. Study Participants. Peripheral blood was obtained from 327 patients with primary SS (91 complicated by B cell NHL (SS-lymphoma), 236 primary SS without the presence of lymphoma (SS-nonlymphoma)) and 448 healthy individuals (HC) of similar age and sex distribution (Table 1). All primary SS patients were classified according to the 2002 revised version of the European criteria proposed by the American European Consensus Group [27] and followed in the Institute of Systemic Autoimmune and Neurological Diseases (Prof. H. M. Moutsopoulos), Department of Pathophysiology, University of Athens and the Rheumatology Department of the General Hospital of Athens "G. Gennimatas" all located in Athens, Greece. Demographic, clinical, and laboratory features were recorded after thorough chart review. Lymphoma diagnosis in the primary SSlymphoma group was based on the criteria outlined by the World Health Organization classification [28], and consisted of 72 patients with mucosa-associated lymphoid tissue (MALT) lymphoma and 19 with non-MALT lymphoma (12 diffuse large B cell lymphoma (DLBCL), 4 nodal marginal zone lymphoma (MZL), 2 small lymphocytic lymphoma (SLL), and 1 MALT that was transformed to T cell lymphoma). This study was carried out in accordance with the recommendations of the Ethics Committee of the National and Kapodistrian University of Athens (approved No. 6337) and Laiko General Hospital of Athens Ethics Committee ( $\Delta \Sigma 12 / 20-4-16)$, with informed consent from all subjects, in accordance with the Declaration of Helsinki. In order to access the ancestry of the study participants, detailed data on family history was collected. Parents and grandparents of $99.4 \%$ of the participants were of Greek ethnic heritage, with the rest being of East European descent. None of the study participants had a non-Caucasian ancestry.

2.2. Clinical, Serological, and Histopathological Characteristics. Demographics and disease-related clinical and laboratory features were recorded at SS diagnosis after thorough chart review as previously described [29].

2.3. DNA Extraction and Genotyping Assay of the TNFAIP3 rs2230926 Variation. Whole blood samples for DNA extraction were collected in ethylene diamine tetraacetic acid (EDTA) tubes from all study subjects at the time of the enrollment. DNA was isolated from blood samples as previously described [29]. The TNFAIP3 variation (rs2230926) was identified with real-time PCR by TaqMan SNP Genotyping Assay (Thermo Fisher Scientific, USA). All samples were tested twice, and the results were $100 \%$ concordant.

2.4. RNA Extraction, cDNA Synthesis, and Quantitation of NF- $\kappa B$-Related Gene Transcripts. Available peripheral blood samples from 165 SS patients as well as from 20 healthy controls (HC) were collected. Total RNA was extracted and reverse transcribed as previously described [29, 30]. Transcripts related to the NF- $\kappa \mathrm{B}$ pathway $(N F-\kappa B 1, N F-\kappa B 2$, $B c l-2$, and $B c l-X L)$ were quantitated by real time PCR (Table 2), as previously described [31]. 


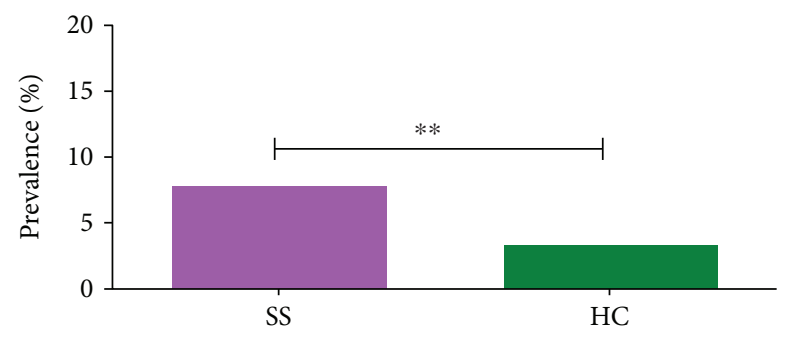

(a)

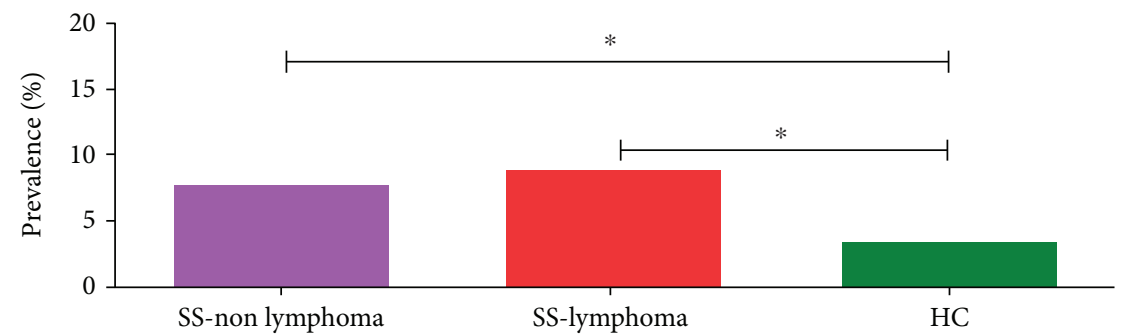

(b)

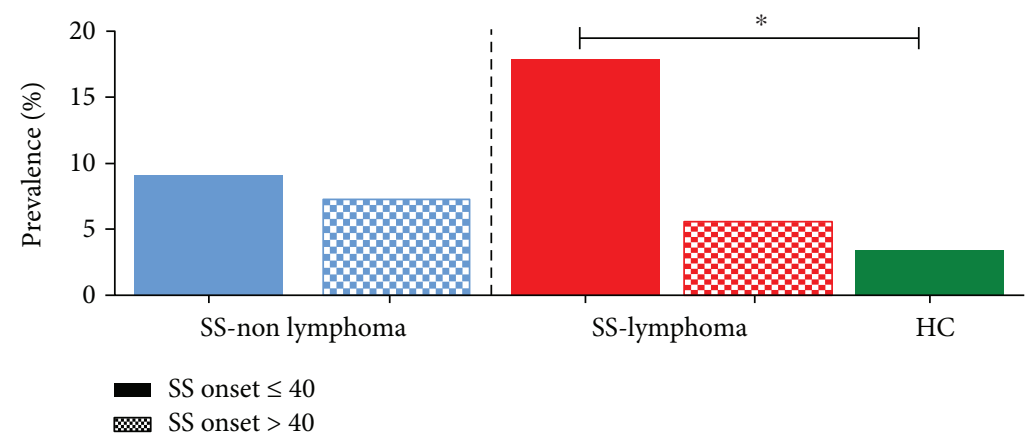

(c)

Figure 1: Prevalence of the rs2230926G single-nucleotide polymorphism in primary Sjogren's syndrome (SS) patients and healthy controls (HC). (a) Increased frequency of the rs $2230926 \mathrm{G}$ variant was detected in all SS study participants compared to HC (26 out of 327 ( $8.0 \%$ ) vs. 16 out of 448 (3.6\%), $p$ value: 0.01 , by Fisher's exact test). (b) Both SS-non lymphoma and SS-lymphoma patients displayed higher rates of the rs 2230926 compared to HC (18 out of $236(7.7 \%)$ and 8 out of 91 (8.8\%) vs. 16 out of 448 (3.6\%), $p$ values: 0.03 and 0.04 , respectively, by Fisher's exact test). (c) When SS subsets were stratified according to the age of SS onset, only the younger-onset ( $\leq 40$ years) subgroup complicated by lymphoma exhibited significantly higher frequencies of the rs2230926G variant compared to HC (4 out of 22 (18.2\%) vs. 16 out of $448(3.6 \%), p=0.01$, by Fisher's exact test).

2.5. Statistical Analysis. The frequency of the rs 2230926 polymorphism was determined in the SS and HC groups, and odds ratios (OR) and 95\% confidence intervals (CI) adjusted for sex and age were calculated. Demographics and clinical and laboratory features, as well as NF- $\kappa \mathrm{B}$ pathway-related gene transcripts, were analyzed for possible associations with the rs2230926 using SPSS v.22.0 and GraphPad Prism. Continuous data were assessed using the Mann-Whitney $U$ test. Categorical data were assessed using Fisher's exact test or chi-square accordingly. Results were considered significant when $p$ value $<0.05$.

\section{Results}

3.1. Increased Prevalence of the rs2230926 Polymorphism in SS Compared to HC. As shown in Figure 1(a), significantly increased rates of the rs2230926 mutant variant were observed in the whole primary SS population compared to HC (26 out of $327(8.0 \%)$ versus 16 out of 448 (3.6\%); OR 2.3 (95\% CI: $1.2-4.4$ ), $p=0.01$, by Fisher's exact test, adjusted for age and sex distribution). Of note, the variation was found only in heterozygous form in all study participants.

We next estimated the prevalence of the rs2230926 variant in the two distinct SS patient groups compared to HC. Both SS-lymphoma and SS-non lymphoma subsets exhibited higher frequencies of TNFAIP3 coding variation compared to HC $(8.8 \%(8 / 91)$ vs. $7.6 \%(18 / 236)$ vs. $3.6 \%$ (16/448), respectively). The calculated OR (95\% CI) for the occurrence of SS-lymphoma and SS-non lymphoma in the presence of the rs2230926 variant was 2.6 (1.16.3), $p=0.04$ and $2.2(1.1-4.2), p=0.03$, respectively (Figure 1(b)). 
The prevalence of the rs2230926 polymorphism in different lymphoma types was the following: $5 / 72$ (6.9\%) in MALT, $1 / 12(8.3 \%)$ in DLBCL, $1 / 4(25 \%)$ in MZL, $0 / 2(0 \%)$ in SLL, and $1 / 1(100 \%)$ in TCL. Due to the small number of patients, no reliable conclusions can be drawn.

Of interest, when SS subsets were further stratified according to the age of SS onset, only the younger-onset ( $\leq 40$ years) subgroup complicated by lymphoma exhibited significantly higher frequencies of the rs2230926G variant compared to HC (4 out of $22(18.2 \%)$ versus 16 out of 448 (3.6\%), OR (95\% CI): 6.0 (1.8-19.8), $p=0.01$ ) (Figure 1(c)). Lymphoma was developed after primary SS diagnosis (mean \pm SD: $15.8 \pm 11.6$ years). Three out of four of patients were complicated by MALT and one by DLBCL.

3.2. Association of the rs2230926 Polymorphism with DiseaseRelated Clinical and Laboratory Characteristics. As shown in Table 3, the rs2230926 variation was found to be negatively associated with age at SS diagnosis $(45.2 \pm 12.9$ years in rs2230926 carriers vs. $51.6 \pm 13.5$ for noncarriers, $p=0.02$ ). While no significant associations were detected between the rs2230926 variant and subjective/objective features of oral and ocular dryness or the presence of anti-Ro/SSA and anti-La/SSB antibodies, lower white blood cell and neutrophil counts and higher LDH and IgM levels were detected in patients carrying the rs2230926 variant compared to the non carriers.

3.3. The rs2230926 Polymorphism and $m R N A$ Expression of the NF- $\kappa B$ Pathway Target Genes in SS Patients. In order to explore potential implications of the TNFAIP3 rs2230926 variation in the NF- $\kappa \mathrm{B}$ pathway, we performed mRNA expression analysis for specific genes of the NF- $\kappa$ B pathway in whole peripheral blood RNA samples from primary SS patients carrying or not the mutant variant. As shown in Figure 2(d), we found significantly higher transcript levels of the antiapoptotic gene $B c l-X L$ in rs2230926 carriers, compared to the group without the mutation $(2.7 \pm 2.1$ vs. $1.6 \pm 2.0, p=0.03$ ), while $B c l-2, N F \kappa-B 1$, and $N F \kappa-B 2$ gene transcripts did not statistically differ between these groups (Figures 2(a)-2(c)).

\section{Discussion}

In the current study, the TNFAIP3 rs2230926 mutant variant emerged as a risk factor for both primary SS and SS-related lymphoma susceptibility. Following stratification by age at disease onset and lymphoma development, we found that the excess of this variation in the primary SS group compared to $\mathrm{HC}$, was mainly attributed to a heightened prevalence in the early-onset primary SS subset complicated by lymphoma, increasing the risk by 6-fold. Moreover, rs2230926 carriers had lower neutrophil but higher LDH and IgM levels at SS diagnosis, as well as increased peripheral blood expression of the antiapoptotic gene $B c l-X L$ possibly related to $N F-\kappa B$ pathway activation.

These data are in accord with previously published observations suggesting that TNFAIP3 rs2230926 coding variation is an additional susceptibility factor for SS [14-16] and
SS-related lymphoma $[12,32]$. Of interest, the prevalence of the TNFAIP3 variation seems to be much lower in our HC cohort compared to both UK and French HC cohorts (3.80\% vs. $7.14 \%$ vs. $12.05 \%$, respectively), implying the presence of a north-south Europe gradient, as previously observed in other autoimmune risk alleles such as the PTPN22 1858C > T variant [33].

Activation of the canonical and noncanonical NF- $\kappa \mathrm{B}$ pathways in transformed $B$ cells following $B$ cell receptor engagement by exogenous or endogenous antigens as well as CD40L and BAFF ligation have been considered a central event in the pathogenesis of extranodal marginal zone lymphoma of mucosa-associated lymphoid tissue (MALT lymphoma), at various anatomical sites such as salivary glands, stomach, and ocular adnexa. Excessive chronic inflammation either related to microbial infections (such as Helicobacter pylori, Chlamydophila psittaci, and Campylobacter jejuni) or autoantigens in a background of both germline and acquired genetic variations have been previously shown to mediate malignant transformation and lymphoma development (reviewed in [34]).

Of interest, the TNFAIP3 rs2230926 variant occurred in one-fifth of the patients with younger-onset SS ( $\leq 40$ years) complicated by lymphoma. Similarly, the His159Tyr mutation of the $B A F F-R$ (which leads to noncanonical NF- $\kappa B$ pathway activation) was found to be present in approximately two-thirds of SS patients with disease onset between 30 to 40 years old with MALT lymphoma [31]. Since data on the presence of the BAFF-R His159Tyr mutation were available in the present cohort from our previous study [31], we calculated the frequency of either mutation in the younger-onset SS ( $\leq 40$ years old) complicated by lymphoma, which was found to be $38.1 \%$ vs. $7.2 \%$ in the older SSlymphoma group increasing the risk by 7.9 -fold in this population (95\% CI: $2.2-28$ ). Taken together, we propose that distinct genetic defects that deregulate both the canonical and the noncanonical NF- $\kappa \mathrm{B}$ pathways in young SS patients may accelerate lymphoma development in the setting of SS, possibly through induction of chronic inflammation, B cell stimulation, and survival. In support of the current findings, published data so far, revealed an aggressive disease phenotype and increased risk of lymphoproliferation among SS patients with young disease onset compared to their older counterparts [35], implying the presence of a distinct genetic background in these individuals.

Given that TNFAIP3 is considered a gatekeeper of the abnormal activation of the NF- $\kappa \mathrm{B}$ pathway, the increased frequency of the TNFAIP3 functional variant in SS patients complicated by lymphoma [12,32] along with the previously reported lower levels of the A20 protein in MSG tissues derived from SS patients complicated by MALT [11] support the idea of A20-related deregulation of $\mathrm{NF}-\kappa \mathrm{B}$ pathways in SS-related lymphomagenesis. As a matter of fact, $B c l-X L$ (which belongs in the Bcl-2 antiapoptotic family as a final target of the NF- $\kappa \mathrm{B}$ pathway) mRNA transcripts were higher in the SS carriers of the rs2230926G variant compared to SS-noncarrier patients, which may be related to the abnormal activation of the NF- $\kappa$ B pathway due to the TNFAIP3 variation providing a survival signal 
TABLE 3: Clinical and laboratory characteristics of primary Sjogren's syndrome (SS) patients according to the presence of the TNFAIP3 rs2230926 variant.

\begin{tabular}{|c|c|c|c|}
\hline & $\begin{array}{c}\text { TNFAIP3 rs2230926 normal } \\
\text { variant }(n=301)\end{array}$ & $\begin{array}{c}\text { TNFAIP3 rs2230926 mutant } \\
\text { variant }(n=26)\end{array}$ & $p$ value \\
\hline \multicolumn{4}{|l|}{ Demographics } \\
\hline Age (mean \pm SD years) & $59.9 \pm 13.7$ & $56.7 \pm 9.0$ & 0.24 \\
\hline Sex, female no. (\%) & $280(93)$ & $27(100)$ & 0.39 \\
\hline Age at SS diagnosis (mean $\pm \mathrm{SD}$, years) & $51.6 \pm 13.5$ & $45.2 \pm 12.9$ & 0.02 \\
\hline \multicolumn{4}{|l|}{ Clinical characteristics } \\
\hline Focus score (no. of foci $\left./ 4 \mathrm{~mm}^{2}\right)($ mean $\pm \mathrm{SD})$ & $2.5 \pm 2.3$ & $3.1 \pm 2.9$ & 0.72 \\
\hline Tarpley score & $2.2 \pm 1.1$ & $2.5 \pm 1.1$ & 0.30 \\
\hline Erythrocyte sedimentation rate (ESR) $(\mathrm{mm} / \mathrm{h})$ & $39 \pm 26$ & $36 \pm 27$ & 0.77 \\
\hline Dry mouth $(\%)$ & $278(92.4)$ & $25(96.2)$ & 0.70 \\
\hline Dry eyes $(\%)$ & $275(91.4)$ & $25(96.2)$ & 0.71 \\
\hline Salivary gland enlargement (SGE) (\%) & $108(35.9)$ & $6(23.1)$ & 0.21 \\
\hline Raynaud's syndrome (\%) & $85(28.3)$ & $8(30.8)$ & 0.82 \\
\hline Lymphadenopathy (\%) & $70(23.3)$ & $6(23.1)$ & 1.00 \\
\hline Splenomegaly (\%) & $11(3.7)$ & $1(3.8)$ & 1.00 \\
\hline Parpable purpura (\%) & $60(19.9)$ & $8(30.8)$ & 0.21 \\
\hline Arthritis (\%) & $79(26.2)$ & $5(19.2)$ & 0.49 \\
\hline Arthralgias/myalgias (\%) & $213(70.8)$ & $19(73.1)$ & 1.00 \\
\hline Interstitial lung disease (\%) & $24(8.0)$ & $4(16.0)$ & 0.25 \\
\hline Liver involvement (autoimmune cholangitis) (\%) & $15(5.0)$ & $1(3.8)$ & 1.00 \\
\hline Kidney involvement (nephrocalcinosis) (\%) & $4(1.3)$ & $1(3.8)$ & 0.34 \\
\hline Lymphoma (\%) & $82(27.3)$ & $8(30.8)$ & 0.82 \\
\hline \multicolumn{4}{|l|}{ Laboratory characteristics } \\
\hline Whole salivary flow $(\mathrm{ml} / 15 \mathrm{~min})($ mean $\pm \mathrm{SD})$ & $1.6 \pm 1.2$ & $1.3 \pm 1.3$ & 0.43 \\
\hline Presence of anti-Ro/SSA autoantibodies (\%) & $223(75.3)$ & $22(88.0)$ & 0.22 \\
\hline Presence of anti-La/SSB autoantibodies (\%) & $123(41.6)$ & $11(44.0)$ & 0.84 \\
\hline Positive rheumatoid factor (\%) & $173(62.9)$ & $14(58.3)$ & 0.67 \\
\hline Low-complement component 4 (C4) levels (<20 mg/dl), no (\%) & $178(60.5)$ & $15(62.5)$ & 0.82 \\
\hline Peripheral blood leucocyte count $\left(\right.$ mean \pm SD per $\left.\mathrm{mm}^{3}\right)$ & $1629.5 \pm 669.2$ & $1566.0 \pm 845.1$ & 0.44 \\
\hline Peripheral blood neutrophil count (mean \pm SD per $\mathrm{mm}^{3}$ ) & $3464.7 \pm 1705.8$ & $2690.4 \pm 628.3$ & 0.009 \\
\hline Peripheral blood monocyte count (mean \pm SD per $\mathrm{mm}^{3}$ ) & $424.0 \pm 228.0$ & $345.9 \pm 165.4$ & 0.18 \\
\hline White blood cell count $\left(\right.$ mean \pm SD per $\left.\mathrm{mm}^{3}\right)$ & $5682.0 \pm 1924.3$ & $4915.8 \pm 1125.7$ & 0.04 \\
\hline Gamma globulin levels (mean \pm SD) & $33.9 \pm 26.2$ & $35.9 \pm 27.1$ & 0.72 \\
\hline Lactate dehydrogenase $(\mathrm{LDH})$ (mean $\pm \mathrm{SD}$ ) levels & $284.6 \pm 122.1$ & $518.2 \pm 238.9$ & 0.005 \\
\hline$\beta 2$-Microglobulin $($ mean \pm SD) & $4.0 \pm 2.6$ & $5.6 \pm 3.5$ & 0.26 \\
\hline Immunoglobulin IgA (mean \pm SD) & $299.8 \pm 146.7$ & $403.3 \pm 194.8$ & 0.21 \\
\hline Immunoglobulin IgG $($ mean $\pm S D)$ & $1683.5 \pm 690.0$ & $2790.0 \pm 1656.7$ & 0.08 \\
\hline Immunoglobulin IgM (mean \pm SD) & $183.1 \pm 125.6$ & $339.8 \pm 308.1$ & 0.02 \\
\hline Presence of monoclonal band (\%) & $34(12.0)$ & $2(8.0)$ & 0.75 \\
\hline Cryoglobulins (\%) & $35(14.1)$ & $4(25.0)$ & 0.27 \\
\hline
\end{tabular}

to $B$ cells. However, we cannot exclude that other gene variants may also account for this finding. The $B c l-X L$ molecule has been found to play a key role in follicular lymphoma. High Bcl-XL levels and low numbers of apoptotic lymphoma cells were reported to be significantly associated with multiple sites of extranodal involvement, elevated lactated hydrogenase level, and short overall survival time [36]. Moreover, $B c l-X L$-overexpressing mice show enhanced survival of B cells [37] whereas Bcl-XL-deficient mice have extensive lymphocyte apoptosis [38].

The strengths of the current study include the complete clinical, serological, and histopathological characteristics of our study participants, the similar age and sex distribution across groups, and the homogeneous Greek Caucasian ancestry (99.4\%). However, certain limitations are also recognized. Due to the relatively small number of SS-lymphoma patients, 


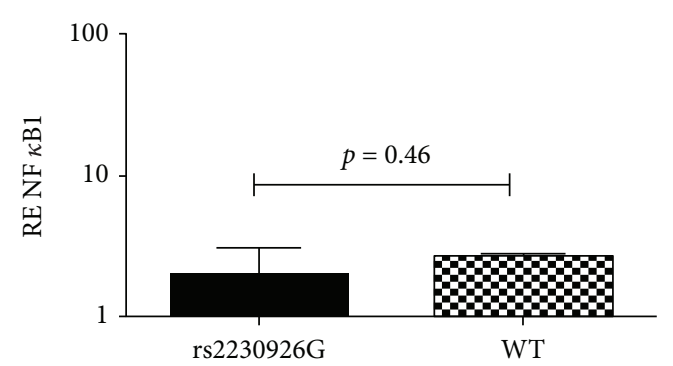

(a)

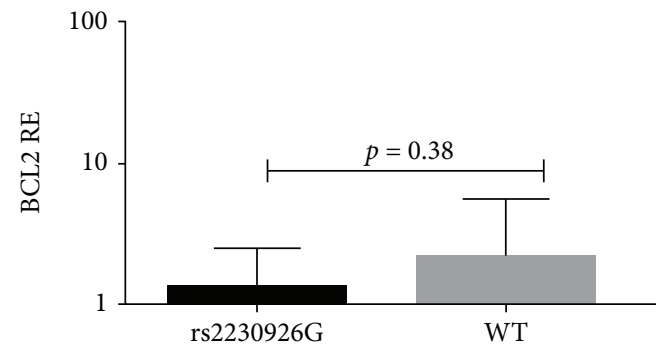

(c)

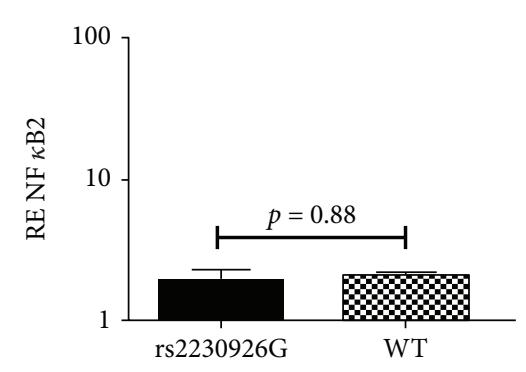

(b)

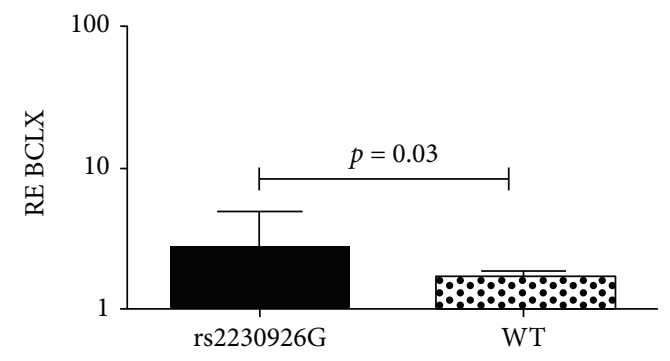

(d)

FIGURE 2: Significantly higher Bcl-XL mRNA transcript levels measured by real time-PCR in the whole peripheral blood of SS patients bearing the rs2230926G variant compared to those without the presence of the polymorphism $(p=0.03)$ (d). No statistically significant differences in $N F K-B 1$ (a), NFK-B2 (b), and Bcl-2 (c) gene expression was detected.

the need for independent validation through multicentric efforts is mandatory. Moreover, more functional experiments are needed to identify the exact role of the rs2230926 A20 genetic variant in SS-related lymphomagenesis. Finally, the presence of other variants in the A20 gene leading to NF$\kappa \mathrm{B}$ pathway activation cannot be excluded.

In conclusion, our data suggest that A20 genetic variants, like rs2230926, may play a central role in the activation of the NF- $\kappa$ B pathway which has been found to be a central pathogenetic event in the malignant transformation in the setting of SS. Elucidation of molecular events leading to SS-related lymphomagenesis will allow eventually the development of tailored therapeutic strategies, opening avenues to personalized medicine approaches.

\section{Data Availability}

All data used to support the findings of this study are included within the article.

\section{Disclosure}

We would like to confirm that part of the results have been included in an abstract for the 2016 ACR/ARHP annual meeting (abstract No. 668, ACR Poster Session, Sunday, November 13, 2016) and cited as a supplement in Arthritis Rheumatol. 2016; 68 (suppl. 10).

\section{Conflicts of Interest}

The authors declare that the research was conducted in the absence of any commercial or financial relationships that could be construed as a potential conflict of interest.

\section{Authors' Contributions}

AN, EG, MK, MV, AGT, and CPM collected clinical and laboratory data from all study participants, analyzed the results, and drafted the manuscript. CPM conceived, designed, and coordinated the study and revised the manuscript. All authors read and approved the final manuscript.

\section{Acknowledgments}

The authors would like to thank Professor H. M. Moutsopoulos for providing DNA samples from SS patients. This study was supported by an Hellenic Rheumatology Society grant to CPM, a Stavros Niarchos Foundation Grant to the Department of Physiology, National and Kapodistrian University of Athens, and the HarmonicSS (European Union Commission project 731944).

\section{References}

[1] C. P. Mavragani and H. M. Moutsopoulos, "Sjögren syndrome," Canadian Medical Association Journal, vol. 186, no. 15, pp. E579-E586, 2014.

[2] C. P. Mavragani and H. M. Moutsopoulos, "Sjögren's syndrome," Annual Review of Pathology: Mechanisms of Disease, vol. 9, no. 1, pp. 273-285, 2014.

[3] A. Papageorgiou, M. Voulgarelis, and A. G. Tzioufas, "Clinical picture, outcome and predictive factors of lymphoma in Sjögren syndrome," Autoimmunity Reviews, vol. 14, no. 7, pp. 641-649, 2015.

[4] E. Zintzaras, M. Voulgarelis, and H. M. Moutsopoulos, "The risk of lymphoma development in autoimmune diseases: a meta-analysis," Archives of Internal Medicine, vol. 165, no. 20, pp. 2337-2344, 2005. 
[5] J. P. A. Ioannidis, V. A. Vassiliou, and H. M. Moutsopoulos, "Long-term risk of mortality and lymphoproliferative disease and predictive classification of primary Sjögren's syndrome," Arthritis and Rheumatism, vol. 46, no. 3, pp. 741-747, 2002.

[6] S. Fragkioudaki, C. P. Mavragani, and H. M. Moutsopoulos, "Predicting the risk for lymphoma development in Sjogren syndrome: an easy tool for clinical use," Medicine, vol. 95, no. 25, article e3766, 2016.

[7] F. N. Skopouli, U. Dafni, J. P. A. Ioannidis, and H. M. Moutsopoulos, "Clinical evolution, and morbidity and mortality of primary Sjögren's syndrome," Seminars in Arthritis and Rheumatism, vol. 29, no. 5, pp. 296-304, 2000.

[8] E. Theander, L. Vasaitis, E. Baecklund et al., "Lymphoid organisation in labial salivary gland biopsies is a possible predictor for the development of malignant lymphoma in primary Sjogren's syndrome," Annals of the Rheumatic Diseases, vol. 70, no. 8, pp. 1363-1368, 2011.

[9] E. Baimpa, I. J. Dahabreh, M. Voulgarelis, and H. M. Moutsopoulos, "Hematologic manifestations and predictors of lymphoma development in primary Sjögren syndrome," Medicine, vol. 88, no. 5, pp. 284-293, 2009.

[10] G. Nocturne and X. Mariette, "Advances in understanding the pathogenesis of primary Sjögren's syndrome,” Nature Reviews Rheumatology, vol. 9, no. 9, pp. 544-556, 2013.

[11] S. J. Johnsen, E. Gudlaugsson, I. Skaland et al., "Low protein A20 in minor salivary glands is associated with lymphoma in primary Sjögren's syndrome," Scandinavian Journal of Immunology, vol. 83, no. 3, pp. 181-187, 2016.

[12] G. Nocturne, S. Boudaoud, C. Miceli-Richard et al., "Germline and somatic genetic variations of TNFAIP3 in lymphoma complicating primary Sjogren's syndrome," Blood, vol. 122, no. 25 , pp. 4068-4076, 2013.

[13] G. Nocturne and X. Mariette, "Sjögren syndrome-associated lymphomas: an update on pathogenesis and management," British Journal of Haematology, vol. 168, no. 3, pp. 317-327, 2015.

[14] C. J. Lessard, H. Li, I. Adrianto et al., "Variants at multiple loci implicated in both innate and adaptive immune responses are associated with Sjogren's syndrome," Nature Genetics, vol. 45, no. 11, pp. 1284-1292, 2013.

[15] Y. Li, K. Zhang, H. Chen et al., "A genome-wide association study in Han Chinese identifies a susceptibility locus for primary Sjögren's syndrome at 7q11.23," Nature Genetics, vol. 45, no. 11, pp. 1361-1365, 2013.

[16] O. D. Konsta, C. le Dantec, A. Charras et al., "An in silico approach reveals associations between genetic and epigenetic factors within regulatory elements in b cells from primary Sjögren's syndrome patients," Frontiers in Immunology, vol. 6, 2015.

[17] M. Zhang, L. L. Peng, Y. Wang et al., "Roles of A20 in autoimmune diseases," Immunologic Research, vol. 64, no. 2, pp. 337-344, 2016.

[18] E. G. Lee, D. L. Boone, S. Chai et al., "Failure to regulate TNF-induced NF- $\kappa \mathrm{B}$ and cell death responses in A20deficient mice," Science, vol. 289, no. 5488, pp. 2350-2354, 2000.

[19] L. Vereecke, R. Beyaert, and G. van Loo, "The ubiquitinediting enzyme A20 (TNFAIP3) is a central regulator of immunopathology," Trends in Immunology, vol. 30, no. 8, pp. 383-391, 2009.
[20] S. L. Musone, K. E. Taylor, T. T. Lu et al., "Multiple polymorphisms in the TNFAIP3 region are independently associated with systemic lupus erythematosus," Nature Genetics, vol. 40, no. 9, pp. 1062-1064, 2008.

[21] S. L. Musone, K. E. Taylor, J. Nititham et al., "Sequencing of TNFAIP3 and association of variants with multiple autoimmune diseases," Genes \& Immunity, vol. 12, no. 3, pp. 176182, 2011.

[22] J. J. Siracuse, M. D. Fisher, C. G. da Silva et al., "A20mediated modulation of inflammatory and immune responses in aortic allografts and development of transplant arteriosclerosis," Transplantation, vol. 93, no. 4, pp. 373-382, 2012.

[23] M. Compagno, W. K. Lim, A. Grunn et al., "Mutations of multiple genes cause deregulation of NF- $\kappa \mathrm{B}$ in diffuse large B-cell lymphoma," Nature, vol. 459, no. 7247, pp. 717-721, 2009.

[24] K. Honma, S. Tsuzuki, M. Nakagawa et al., “TNFAIP3/A20 functions as a novel tumor suppressor gene in several subtypes of non-Hodgkin lymphomas," Blood, vol. 114, no. 12, pp. 2467-2475, 2009.

[25] M. Kato, M. Sanada, I. Kato et al., "Frequent inactivation of A20 in B-cell lymphomas," Nature, vol. 459, no. 7247, pp. 712-716, 2009.

[26] M. Sisto, S. Lisi, D. D. Lofrumento, G. Ingravallo, E. Maiorano, and M. D'Amore, "A failure of TNFAIP3 negative regulation maintains sustained NF- $\kappa$ B activation in Sjögren's syndrome," Histochemistry and Cell Biology, vol. 135, no. 6, pp. 615-625, 2011.

[27] C. Vitali, S. Bombardieri, R. Jonsson et al., "Classification criteria for Sjogren's syndrome: a revised version of the European criteria proposed by the American-European Consensus Group," Annals of the Rheumatic Diseases, vol. 61, no. 6, pp. $554-558,2002$.

[28] E. S. Jaffe, "The 2008 WHO classification of lymphomas: implications for clinical practice and translational research," Hematology, vol. 2009, no. 1, pp. 523-531, 2009.

[29] N. I. Vlachogiannis, A. Nezos, A. G. Tzioufas, M. Koutsilieris, H. M. Moutsopoulos, and C. P. Mavragani, "Increased frequency of the PTPN22W* variant in primary Sjogren's syndrome: association with low type I IFN scores," Clinical Immunology, vol. 173, pp. 157-160, 2016.

[30] A. Nezos, F. Gravani, A. Tassidou et al., "Type I and II interferon signatures in Sjogren's syndrome pathogenesis: contributions in distinct clinical phenotypes and Sjogren's related lymphomagenesis," Journal of Autoimmunity, vol. 63, pp. 47-58, 2015.

[31] A. Papageorgiou, C. P. Mavragani, A. Nezos et al., "A BAFF receptor His159Tyr mutation in Sjögren's syndrome-related lymphoproliferation," Arthritis \& Rheumatology, vol. 67, no. 10, pp. 2732-2741, 2015.

[32] G. Nocturne, J. Tarn, S. Boudaoud et al., "Germline variation of TNFAIP3 in primary Sjögren's syndrome-associated lymphoma: Table 1," Annals of the Rheumatic Diseases, vol. 75, no. 4, pp. 780-783, 2016.

[33] M. C. Totaro, B. Tolusso, V. Napolioni et al., "PTPN22 $1858 \mathrm{C}>\mathrm{T}$ polymorphism distribution in Europe and association with rheumatoid arthritis: case-control study and metaanalysis," PLoS One, vol. 6, no. 9, article e24292, 2011.

[34] M. Q. Du, "MALT lymphoma: a paradigm of NF- $\kappa$ B dysregulation," Seminars in Cancer Biology, vol. 39, pp. 49-60, 2016. 
[35] M. Ramos-Casals, R. Cervera, J. Font et al., "Young onset of primary Sjögren's syndrome: clinical and immunological characteristics," Lupus, vol. 7, no. 3, pp. 202-206, 1998.

[36] W. L. Zhao, M. E. Daneshpouy, N. Mounier et al., "Prognostic significance of bcl-xL gene expression and apoptotic cell counts in follicular lymphoma," Blood, vol. 103, no. 2, pp. 695-697, 2004.

[37] D. A. Grillot, R. Merino, J. C. Pena et al., "Bcl-X exhibits regulated expression during $\mathrm{B}$ cell development and activation and modulates lymphocyte survival in transgenic mice," Journal of Experimental Medicine, vol. 183, no. 2, pp. 381-391, 1996.

[38] N. Motoyama, F. Wang, K. Roth et al., "Massive cell death of immature hematopoietic cells and neurons in Bcl-X-deficient mice," Science, vol. 267, no. 5203, pp. 1506-1510, 1995. 


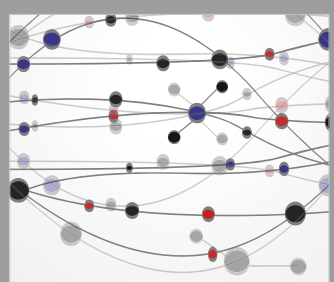

The Scientific World Journal
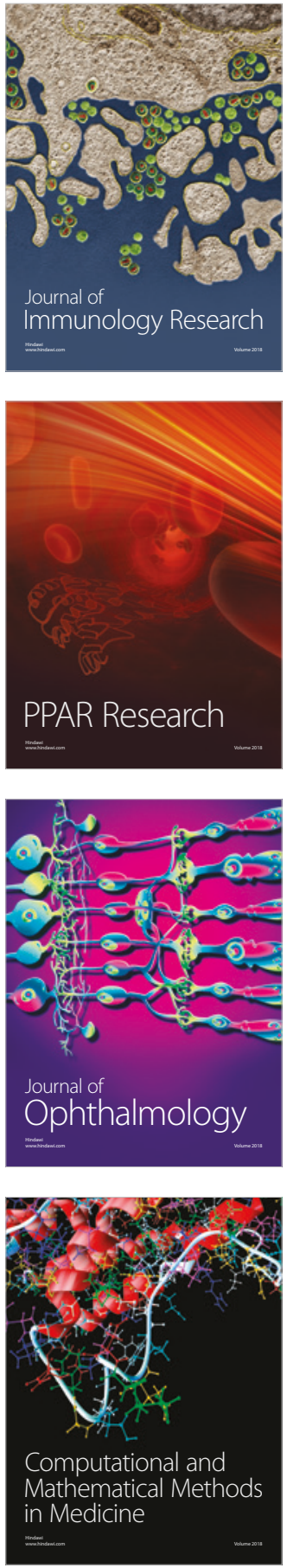

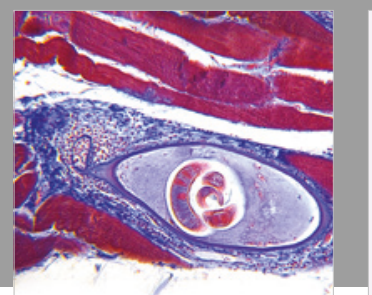

Gastroenterology Research and Practice

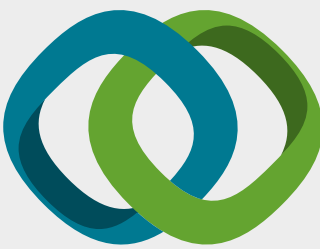

\section{Hindawi}

Submit your manuscripts at

www.hindawi.com
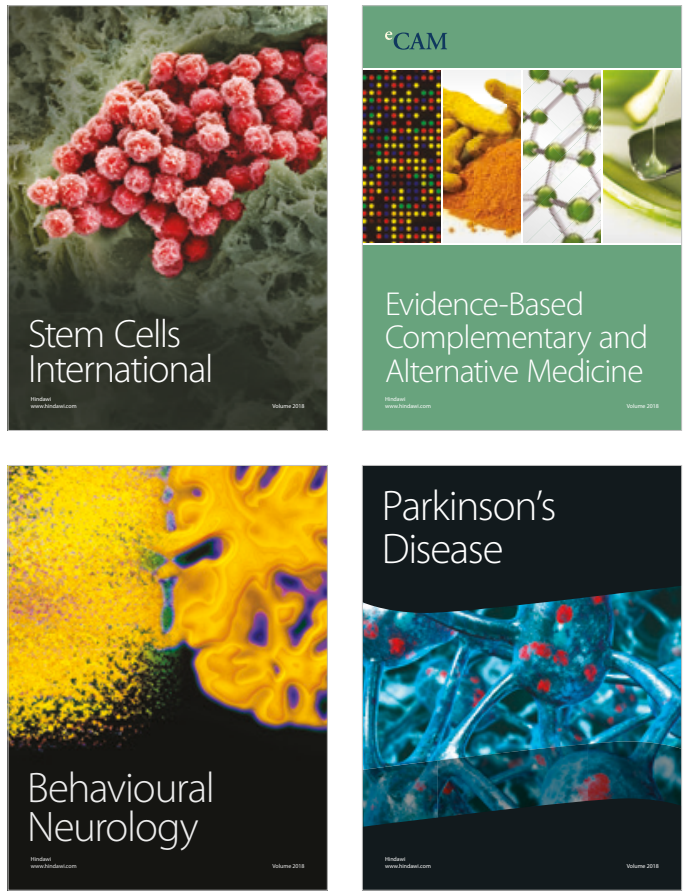

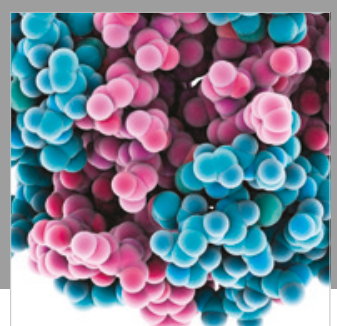

ournal of

Diabetes Research

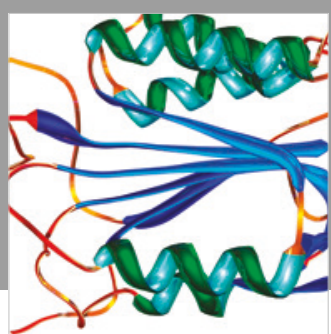

Disease Markers
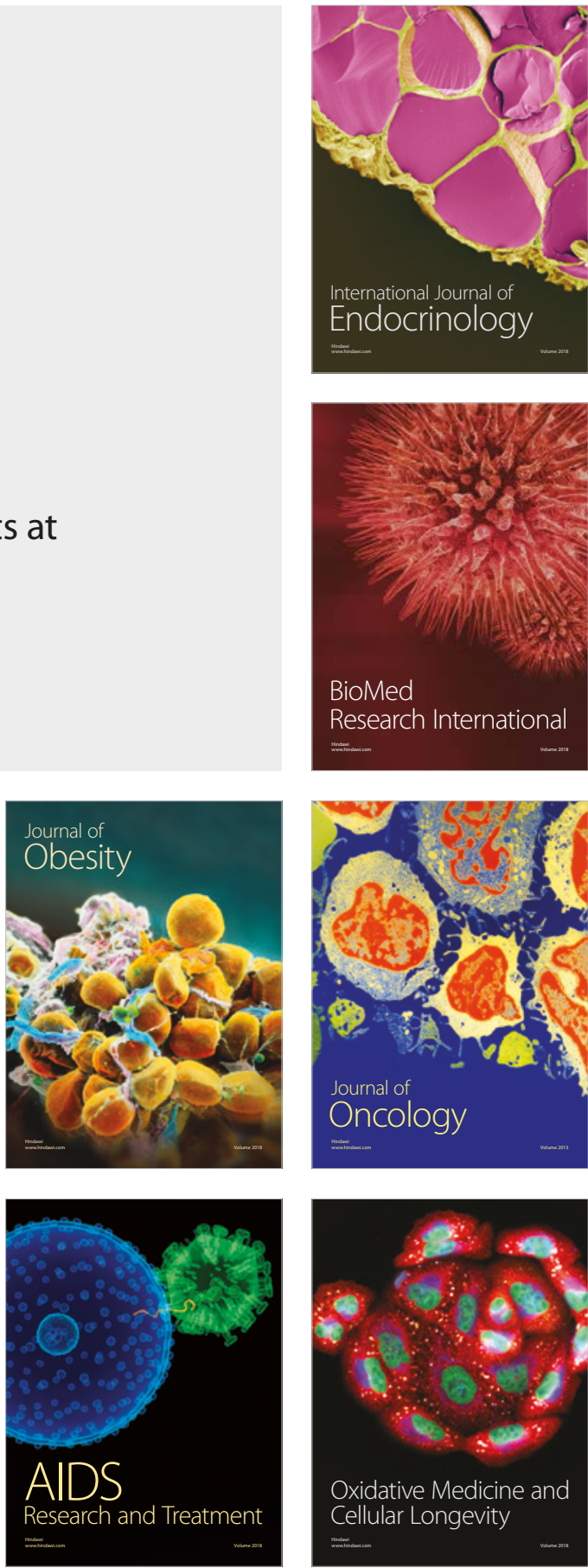